\title{
Hypoglycemic and Hypolipidemic Activities of Psychotria sylhetensis Hook in Alloxan-induced Type 2 Diabetic Rats
}

\section{Israt Jahan Bulbul ${ }^{1,2}$, Umma Shafia Joty ${ }^{1}$, Ridoy Ahamed ${ }^{1}$, Mohammad Rashedul Haque $^{2}$ and Mohammad A. Rashid ${ }^{2}$}

\author{
${ }^{1}$ Department of Pharmacy, Southeast University, Banani, Dhaka-1213, Bangladesh \\ ${ }^{2}$ Department of Pharmaceutical Chemistry, Faculty of Pharmacy, University of Dhaka \\ Dhaka-1000, Bangladesh
}

(Received: June 16, 2018; Accepted: September 14, 2018; Published: January 17, 2019)

\begin{abstract}
The current study was carried out to determine the hypoglycemic and hypolipidemic activities of methanolic extract $P$. silhetensis leaves in alloxan-induced diabetic rats. In this study diabetes was induced in rats by intraperitoneal administration of $150 \mathrm{mg} / \mathrm{kg}$ of alloxan. Animals were treated for one week with the plant extract at doses of 250 and $500 \mathrm{mg} / \mathrm{kg}$ body weight. Metformin (100 mg/kg b.w.) was used as standard for comparison. The anti-diabetes activity was examined by measuring blood glucose level at 0, 3, 5 and 7 days in diabetic induced animal models. Blood samples were collected at day eight of the treatment and analyzed for triglyceride (TG), total cholesterol (TC), high density lipoprotein cholesterol (HDL-C) and low density lipoprotein cholesterol (LDL-C) after sacrifice. Alloxan-induced diabetic rats exhibited a significant decrease in plasma glucose level when treated with $P$. silhetensis leaf extract as compared to normal, diabetic control and standard rats. All tested lipid parameters were improved after the treatment with methanolic extract of $P$. silhetensis and metformin as compared to diabetic rats. The results of the present study showed that $P$. silhetensis possesses significant anti-diabetic properties and has beneficial effects on diabetic hyperlipidemia.
\end{abstract}

Key words: Psychotria silhetensis, alloxan, hypoglycemic, hypolipidemic.

\section{Introduction}

Diabetes is a metabolic disorder and responsible for significant morbidity and mortality due to severe complications such as neuropathy heart attack, nephropathy, stroke and peripheral vascular diseases. Worldwide, there are about 415 million people suffering from diabetes worldwide. According to a research published in WHO bulletin in 2013, Bangladesh has a disproportionately high diabetic population (more than 7.1 million). The urban people are slightly more prone to diabetes than the rural people. Poor and illiterate urban people experience great difficulties paying for needed health care services for diabetes. So they rely on herbal medicines for its inexpensive, easily accessible and well-established health benefits and the use of plant based medicines is an integral part of public health services in Bangladesh (Ashraf et al., 1982; Ahmed et al., 2009; Rahman et al., 2012).

Psychotria is a genus of flowering plants in the Rubiaceae family. It contains around 1600 species and therefore one of the largest genera of flowering plant. An increasing number of phytochemical studies have been investigated belonging to the genus Psychotria in the last few years contributing significantly to the ethnobotanical, pharmacological and chemotexonomic studies in addition to the molecular phylogenetic analysis (Nepokroeff et al., 1999). The genus Psychotria can be characterized as an abundant source of monoterpene, indole, quinolone and isoquinolone alkaloids as well as flavonoids, coumarins, terpinoids and cyclic peptides

Correspondence to: Mohammad A. Rashid, E-mail: r.pchem@yahoo.com; Tel.: +88-02-9661900-73, Extn. 8137. 
that might have wide range of biological activities such as antidiabetic, hypolipidemic, antifungal, antiviral, anti-diarrheal (Pimenta et al., 2011). Some species from Psychotria genus contains harmane (alkaloid), kaempferol, rutin, quercetin (flavonoids), $\alpha$-amyrin, $\beta$-sitosterol (terpinoids) in various concentrations. All of these phytochemicals are used in the treatment of diabetes mellitus.

$P$. sylhetensis Hook is a species of the genus Psychotria which is a shrub that grows on tropical moist forest. In Bangladesh, this shrub is found in the hill tracks of Chittagong, Moulvibazar, Rangamati and Sylhet. Since many species from Psychotria genus contains compounds having antidiabetic activity, it is possible to have antidiabetic activity of $P$. silhetensis. As part of our continuing investigation on medicinal plants of Bangladesh (Bulbul et al., 2016 and Bulbul et al., 2017) the crude methanol extract of $P$. sylhetensis leaves was studied for hypoglycemic and hypolipidemic activities for the first time.

\section{Methods}

Collection of plant materials: The leaves of $P$. silhetensis Hook were collected from Moulvibazar in April 2017 and identified at Bangladesh National Herbarium, Mirpur, Dhaka, where a voucher specimen has been submitted under the accession number 43914.

Extraction: The plant powder ( $250 \mathrm{~g})$ was taken in a flat bottom round flask and soaked in 1.5 liter of methanol. The bottle with its content was sealed and the mixture was allowed to stand for 7 days with occasional shaking. The extract was then filtered through cotton and then through Whatman Number 1 filter paper. The filtrate was concentrated with a rotary evaporator under reduced pressure at $50^{\circ} \mathrm{C}$ temperature to afford the crude extract. Then the crude extract was kept on a water bath which provided a gummy concentrate. The extract was then allowed to evaporate to dryness to obtain $37 \mathrm{~g}$ of crude residue (yield: 14.8\%).

Animals: Three weeks old male and female Long Evan rats weighing 60-140 g were obtained from the International Centre for Diarrhoeal Disease Research Bangladesh (icddr,b). All animal cases were kept under standard environmental condition (22-25 $5^{\circ}$, humidity 40-60\%, $12 \mathrm{~h}$ light: $12 \mathrm{~h}$ dark cycle). The animals had free access to water and standard rat diet. All procedures were performed according to our institutional guidelines for animal experimentation.

Induction of diabetes: Animals were allowed to fast for $12 \mathrm{hrs}$. The rats were injected alloxan monohydrate dissolved in sterile normal saline at a dose of $150 \mathrm{mg} / \mathrm{kg}$ body weight, intraperitoneally. Since alloxan is capable of producing fatal hypoglycemia as a result of massive pancreatic insulin release, rats were treated with $10 \%$ glucose solution intraperitoneally after $6 \mathrm{hrs}$ of alloxan injection. After 3 days, blood glucose level was measured by using glucose monitoring devise (ACCU-CHEK Active). The rats with blood glucose level greater than or equal to $7 \mathrm{mmol} / \mathrm{l}$ were selected for the study. The blood sample was collected from tail vein of the rats.

Experimental design: Hypoglycemic activity was evaluated as described by Sekar et al. (1990) in the present experiment where, 20 rats (16 diabetic surviving rats, 4 normal rats) were used. Diabetes was induced in rats 3 days before starting the treatment. The Long Evan rats were divided into five groups as normal control (non-dibetic), diabetic control (untreated), standard control (Metformin 100 $\mathrm{mg} / \mathrm{kg}$ b.w.), P. sylhetensis extract at two different doses (250- and 500- $\mathrm{mg} / \mathrm{kg}$ b.w.) after the induction of diabetes and each group comprised of 4 rats. The animals were carefully monitored every day. The test drug and extract were administered orally for one week. Fasting blood glucose estimation, body weight, food and water intake were monitored on day 0, 3, 5 and 7 day of the study. On day eighth, the rats were sacrificed by cervical dislocation under chloroform anaesthesia. Blood samples were collected from overnight fasted rats and processed for the estimation of serum glucose and serum lipids profile. The concentration of total glucose (TG), total cholesterol (TC), low density lipid (LDL) and high density lipid 
(HDL) cholesterol were measured colorimetrically by blood analyser using commercially available wet reagent diagnostic kits (HUMAN GmbH, Germany).

Statistical analysis: Statistical analysis was carried out in one-way ANOVA followed by posthoc Dunnet test and the data are expressed in mean \pm SEM. Comparisons with $\mathrm{p}$ values $<0.05$ were considered to be statistically significant.

\section{Results and Discussion}

Effect of Psychotria silhetensis on blood glucose level: The effect of methanolic extract of $P$. silhetensis leaves and metformin on blood glucose level in alloxan induced Long-Evans diabetic rats after one week of continuous treatment is shown in table 1. Injection of alloxan caused an increase in blood glucose concentration in all group of rats as compared to their respective baseline blood glucose and to control values. At all-time, blood glucose concentration remained unchanged in normal rats. However, oral administration of the plant extract as well as standard metformin to diabetic rats significantly decreased in blood glucose concentration. The blood glucose concentration was decreased by $65.40,36.66$ and $58.89 \%$ when treated with metformin, $250 \mathrm{mg}$ of extract and $500 \mathrm{mg}$ of extract, respectively as compared to untreated diabetic rats.

Table 1. Effect of $P$. silhetensis on blood glucose level in alloxan-induced type 2 diabetic rats.

\begin{tabular}{lccccc}
\hline \multirow{2}{*}{ Groups } & \multicolumn{5}{c}{ Day of treatment } \\
\cline { 2 - 5 } & $\begin{array}{l}\text { At the time } \\
\text { of grouping }\end{array}$ & Day 0 & Day 3 & Day 5 & Day 7 \\
\hline & \multicolumn{7}{c}{ Fasting Blood glucose level (mmol/L) } \\
\hline Control & 4.12 & $4.77 \pm 0.36$ & $4.45 \pm 0.90$ & $4.73 \pm 0.36$ & $4.02 \pm 0.26$ \\
Untreated diabetic & 4.71 & $8.92 \pm 0.79$ & $9.1 \pm 0.65$ & $10.1 \pm 1.19$ & $14.5 \pm 2.02$ \\
$\begin{array}{l}\text { Diabetic }+ \text { metformin } \\
(100 \mathrm{mg} / \mathrm{kg} \text { b.w.) }\end{array}$ & 5.23 & $8.42 \pm 0.54^{*}$ & $6.65 \pm 0.60$ & $4.6 \pm 0.23^{\#}$ & $5.06 \pm 0.23^{\#}$ \\
$\begin{array}{l}\text { Diabetic }+ \text { P. silhetensis } \\
(250 \mathrm{mg} / \mathrm{kg} \text { b.w.) }\end{array}$ & 5.5 & $10.22 \pm 0.52^{*}$ & $9.4 \pm 1.80^{*}$ & $8.3 \pm .12^{*}$ & $9.2 \pm 0.26^{* \#}$ \\
$\begin{array}{l}\text { Diabetic }+ \text { P. silhetensis } \\
(500 \mathrm{mg} / \mathrm{kg} \text { b.w.) }\end{array}$ & 4.5 & $11.7 \pm 1.7^{*}$ & $11.33 \pm 1.4^{*}$ & $8.3 \pm 0.8^{*}$ & $5.97 \pm 0.8^{* \#}$ \\
\hline
\end{tabular}

Values are means $\pm \mathrm{SEM}$; number of animals per group $=4$. $^{*} \mathrm{p}<0.05$ significantly different compared to control. $\# \mathrm{p}<0.05$ significantly different compared to untreated diabetic.

Effect of $P$. silhetensis on lipid profile: The effects of $P$. silhetensis leaf extract on TG, TC, HDL$\mathrm{C}$ and LDL-C in alloxan induced diabetic rats are shown in table 2. After alloxan induction, the untreated diabetic rats showed marked increase in the level of serum glucose, total cholesterol, triglycerides and LDL-C when compared to the normal control rats. But, HDL-C level was decreased in untreated diabetic rats when compared with the normal control rats. On the other hand, treatment with $P$. silhetensis extract, the alloxan-induced diabetic rats at two different doses (250- and 500- $\mathrm{mg} / \mathrm{kg}$ b.w.) for 7 days revealed a decline in serum lipid profile in a dosedependent manner. The levels of TC, LDL-C were $27.76 \%, 91.72 \%$ in case of $250 \mathrm{mg} / \mathrm{kg}$ b.w. whereas
$52.63 \%, 91.90 \%$ respectively for $500 \mathrm{mg} / \mathrm{kg} \mathrm{b.w.}$ when compared to untreated diabetic rats. The levels of HDL-C rise in the groups treated with $P$. silhetensis leaf extract (250- and 500- $\mathrm{mg} / \mathrm{kg}$ b.w.) as 4.95 and $33.52 \%$, respectively compared to untreated diabetic group. Nevertheless, standard drug metformin $(100 \mathrm{mg} / \mathrm{kg} \mathrm{b.w})$ treatment showed 15.92 , 36.79 and $58.06 \%$ decrease in TC, TG, LDL-C, respectively and $58.31 \%$ increase in HDL-C when compared to untreated diabetic groups. There was an increase in TG level in rats treated with $P$. silhetensis extract of 250 and $500 \mathrm{mg} / \mathrm{kg}$ b.w. (28.84 and $11.02 \%$, respectively) compared to untreated diabetic rats. This might be due to mechanical error, so further studies should be done in case of TG reading. 
Table 1. Effects of $P$. silhetensis on lipid profile in alloxan-induced type 2 diabetic rats.

\begin{tabular}{|c|c|c|c|c|c|c|c|}
\hline \multirow{2}{*}{ Group } & \multicolumn{2}{|c|}{ Body wt. (g) } & \multirow{2}{*}{$\begin{array}{c}\text { Organ wt. } \\
(\mathrm{mg} / \mathrm{g})\end{array}$} & \multicolumn{4}{|c|}{ Lipid profile (mmol/l) } \\
\hline & Initial & Final & & TG & TC & HDL-C & LDL-C \\
\hline Control & 75 & 93 & 4.73 & $4.57 \pm 0.34$ & $4.47 \pm 0.40$ & $7.67 \pm 0.83$ & $1.97 \pm 0.13$ \\
\hline Untreated diabetic & 97 & 90 & 4.15 & $6.17 \pm 0.25$ & $10 \pm 1.03$ & $5.95 \pm 0.77$ & $9.3 \pm 0.84$ \\
\hline $\begin{array}{l}\text { Diabetic + metformin } \\
\text { (100 mg/kg b.w.) }\end{array}$ & 82 & 94 & 4.49 & $3.9 \pm 0.3$ & $8.4 \pm 0.5^{\#}$ & $9.4 \pm 0.74^{\#}$ & $3.9 \pm 0.1^{* \#}$ \\
\hline $\begin{array}{l}\text { Diabetic }+ \\
\text { P.silhetensis }(250 \\
\mathrm{mg} / \mathrm{kg} \text { b.w.) }\end{array}$ & 100 & 112 & 5.50 & $7.9 \pm 1.05$ & $7.2 \pm 0.4^{* \#}$ & $6.2 \pm 0.8$ & $0.77 \pm .10^{\text {*\# }}$ \\
\hline $\begin{array}{l}\text { Diabetic }+ \\
\text { P.silhetensis }(500 \\
\text { mg/kg b.w.) }\end{array}$ & 104 & 122 & 6.1 & $6.8 \pm .80^{\#}$ & $4.7 \pm 0.7^{*}$ & $7.9 \pm 1.1$ & $0.75 \pm 0.1^{* \#}$ \\
\hline
\end{tabular}

Values are means \pm SEM; number of animals per group $=4$. $^{*} \mathrm{p}<0.05$ significantly different compared to control.

$\#$ p $<0.05$ significantly different compared to untreated diabetic.

\section{Conclusion}

In conclusion, the methanolic extract of $P$. silhetensis has been able to reduce elevated blood glucose, cholesterol, low density lipid and to increase blood level of high density lipid in alloxan treated diabetic rats. Thus future study with this plant is required to identify the pure secondary metabolites responsible for these bioactivities in animal model and further understanding the mechanism of these activities.

\section{References}

Ahmed, S.M., Hossain, M.A. and Chowdhury, M.R. 2009. Informal sector providers in Bangladesh: how equipped are they to provide rational health care? Health Policy Plan. 24, 467-478.

Ashraf, A., Chowdhury, S. and Streefland, P. 1982. Health, disease and health-care in rural Bangladesh. Soc. Sci. Med. 16, 2041-2054.

Bulbul, I.J., Khan, M.F., and Rashid, M.A. 2016. Analgesic and central nervous system depressant activities of methanol extract of Ziziphus rugosa Lam. leaves. Afr. J. Pharm. Pharmacol. 10, 849-853.
Bulbul, I.J., Fashiuddin S.B., Haque M.R., Sultan M.Z. and Rashid M.A. 2017. Anti-nociceptive and Antiinflammatory Activities of Crotalaria pallida Aiton (Fam: Fabaceae) leaves. Bangladesh Pharm. J. 20, 165-171.

Nepokroeff, M. Bremer, B. and Sytsma, K. 1999. Reorganization of the genus Psychotria and tribe Psychotrieae (Rubiaceae) inferred from ITS and rbcl sequence data. Syst. Bot. 24, 5-27.

Pimenta, A.T.A., Uchôa, D.E.A., Braz-Filho, R., de Souza, E. B., Silveira, E. R. and Lima, M.A.S. 2011. The genus Psychotria: phytochemistry, chemotaxonomy, ethnopharmacology and biological properties. J. Barz. Chem. Soc. 22, 2216.

Rahman, S.A. Kielmann, T. McPake and B. Normand, C. 2012. Healthcare-seeking behaviour among the tribal people of Bangladesh: can the current health system really meet their needs? J. Health Popul. Nutr. 30, 353-365.

Sekar, N., Kanthasamy, A., William, S., Subramanian, S. and Govindasamy, S. 1990. Insulinic actions of vanadate in diabetic rats. Pharmacol. Res. 22, 207217. 